\title{
On Demanding the Authorship of a Translator: A Scrutiny of why and how the Translator should be Judged in Relation to the Author
}

\author{
Mossa. Sohana Khatun \\ Adjunct Lecturer, Department of English Literature and Language (ELL), Northern University Bangladesh \\ (NUB), Banani, Dhaka \\ *Corresponding Author: Mossa. Sohana Khatun, Adjunct Lecturer, Department of English Literature \\ and Language (ELL), Northern University Bangladesh (NUB), Banani, Dhaka
}

\begin{abstract}
The task of translation has been always underestimated as a secondary activity on the ground that a translator does not have to put as much labor as that of an author while translating a text. This tendency is rooted into the restrictions set by different theorists of translation who prescribe a 'word-for-word' approach for the translators. The present paper attempts to show the futility of these restrictions and set the demand that a translator should be given similar value and respect as an author since any work of translation demands equal, and sometimes more, creativity and hard work from the part of the translator. Special emphases have been given on the illusiveness of a text's originality and the creative nature of a translation.
\end{abstract}

Keywords: Translator, Author, Originality, Creativity, Re-Creation, Decentre, Faithfulness, Hybridization.

\section{INTRODUCTION}

The practice of literary translation dates back to a time in the history of mankind when the theories of translation did not even lurk into the minds of the scholars associated with it. A possible reason might be that the practice of literary translation did not emerge just as another fashion in the literary area; rather, it sprout out of different necessity- mostly political, historical, religious and above all, cultural. Greek civilization had to travel through a complicated channel to reach the realm of English culture. Initially, the Romans subsumed the Greek civilization by the Roman translation of Greek texts. Later, the Greek and Roman classics were translated and preserved in Arabic by the Arabians. In the $13^{\text {th }}$ century, Michael Scott, "an important philosopher at the Court of the Holy Roman Emperor" and an assumed graduate from Oxford seized the opportunity of learning Arabic during one of his cultural tours in Spain and translating the works of the Arabic translations of Greek texts into English, especially, the works of Aristotle. (Famous Scots - Michael Scott the Wizard (? - 1236?), n.d.: para. $1 \& 3)$

Most of the texts during the Old and Middle English period were written in Latin. It is King Alfred, the Great, who first translated Venerable Bede's The Ecclesiastical History of the English People around the $9^{\text {th }}$ century in order to make his subjects concerned about the ups and downs of civilizations. Another period of translation led to the European Renaissance in the $15^{\text {th }}$ and $16^{\text {th }}$ centuries. However, The Bible is the example of one text being translated into different languages for all the above-mentioned purposes, i. e. religious, political, historical and cultural. From the beginning, the task of translation has been used as a tool of exchanging ideas and medium of interaction, but there has always been a hierarchy at work. Translation in history has been considered to be a secondary activity of lesser value in relation to the original or target text. Translators have never been considered writers or authors in their own right. Hence, the purpose of the present paper is to advocate for acknowledging the authorship of a translator on the ground that the task of literary translation demands similar amount of hardship and investment of creativity to that of an author.

\section{Statement of Problem}

Formal theories of translation began in the $16^{\text {th }}$ and $17^{\text {th }}$ centuries- much after the practice of translation itself emerged. Prior to that period, we have only some sporadic comments on how 
On Demanding the Authorship of a Translator: A Scrutiny of why and how the Translator should be Judged in Relation to the Author

translation activity should be approached. Some of them presented the theories in the form of logics to justify and rationalize their own ways of translating a particular literary piece. Starting from Cicero and St. Jerome, and continuing through the views of Martin Luthar, George Chapman, John Dryden, John Benham, Alexander Pope and others, the approach towards translation has been suggested grossly into two ways- 'word-for word' and 'sense-for-sense'. Some of the commentators and theorists were on behalf of 'word-for-word' approach, while others advocated for 'sense-for-sense'. Whatever the preferences were, none has considered the task of a translator of equal value with respect to that of the author. A border-line has always been drawn between the author and the translator to imply the derivational and subordinate nature of a translated text and the translator.

Translation has been undermined as "derivative", "an echo of the original text", "artificial", "false", "treasonous", "ill-fitting clothing" and so on, but the worst of them is gender metaphoric over time (Chamberlain 2000: 307). In order to place the work of translation in a subordinate position, different theorists of translation have brought up gender metaphoric of translation. Lori Chamberlain (2000) has very skillfully described how the work of a translation has been treated as female in comparison to the dominating male, which is obviously the original text and thus pushing it towards the hostility of patriarchy. The characteristics of the task of translation are similar to that of a beautiful lady who is usually unfaithful to her lord (Les belle infidèles). Different theorists such as the Earl of Roscommon, Thomas Franklin, William Cowper, Friedrich Schleiermacher have compared the translator as female subordinate to the author of the original text, while some others have compared both the author and the translator as male and the text with female which is to be seduced, thus comparing the task of translation as an act of seduction (Chamberlain 2000: 308). Some of them have also questioned the legitimacy of translation on the basis that any attempt to tamper with the natural mother tongue is immoral (Chamberlain 2000: 309). Chamberlain (2000) has discovered a reason for this demeaning treatment with the task of translation. She suspects that it is the usual fear of patriarchy of losing power and control. If the translator does not remain faithful to the original text, s/he may eventually dethrone and decentre the author and the original text. Thus, the original text risks losing "its phallus, the sign of paternity, authority, and originality" (p. 315).

The translator is denied his/her authorship often on the ground that he/she does not have to invest much labour, creativity and imagination. However, any thoughtful and prudent person will notice the fact that while translating a text, it is the translator's creativity that is at stake; partly because $s /$ he has to try hard so that the author's creativity remains intact, and partly because s/he has to fight against her/his own creative potentials and imagination so that they cannot intervene those of the author (The translator's creative and imaginative potentials win over her/his restraints ultimately). By denying the authorship of a translator, we underestimate his creative skills and potentials. Now, one may ask why a translator takes the risk. There are lots of reasons behind this. Among them, the focus will be primarily on the cultural and "global" ones in this study. The translator's role is similar to that of a volunteer. A volunteer does not play the main role or perform in an event, yet her/his role can never be denied in observing any event with success and maintain order in it. In this case, the event where the translator plays the role of a volunteer is globalization. Until people of one country get acquainted with the people and culture of other countries, the attempts to reach the aim of globalization will be hindered. For example, if a Bangladeshi wants to read Les Miserable, what does s/he do? It is only a Bangla or English translation of the book that would suffice. Only then we may hope to line up all the inhabitants of the earth on the same platform.

\section{The True Nature of a TeXT}

In order to establish the existence of an author, we must assume that her/his work is original. If we consider Julia Kristeva's (1986) concept of inter textuality, we will be surprised to notice that there is no original text, because "any text is the absorption and transformation of another" (p. 37). There is no text that can stand alone. It implies that there is a network of texts within which all the texts ever written are interwoven. One text refers back to another within that network. Thus she has challenged the notion of origin, thus the notion of authorship. We find a similar viewpoint in T. S. Eliot's "Tradition and Individual Talent" (1921) where he has promoted the idea that any writing is the combination of reference to previous works and 'individual talent'. This also implies that no writing is independent. Susan Bassnett (1980) refers to Anne Cluysenaar's structuralist approach which asserts that any literary text consists of interwoven linguistic structures where one part is related to another (p. 80). She also cites Robert Scholes who sounds very explicit in this regard- 
On Demanding the Authorship of a Translator: A Scrutiny of why and how the Translator should be Judged in Relation to the Author

Every literary unit from the individual sentence to the whole order of words can be seen in relation to the concept of system. In particular we can look at individual works, literary genres, and the whole of literature as related systems and at literature as a system within the larger system of human culture (as cited in Bassnett 1980: 80).

Bassnett substantiates her hypothesis drawing on Octavio Paz who contends that all texts are 'translations of translations of translations' as they are part of a literary system-

Every text is unique and, at the same time, it is the translation of another text. No text is entirely original because language itself, in its essence is already a translation: firstly, of the non-verbal world and secondly, since every sign and every phrase is the translation of another sign and another phrase (as cited in Bassnett 1980: 44).

In Plato's The Republic (1987), the character of Socrates too dwells on the unavailability of anything original. There is nothing called original. Everything we see in the world is an image of the original. Plato hypothesizes that in this world of shadows, we can only experience the shadows of the Forms, not the Ideal Forms (p. 476f). All we have here is the mime, the corruption of the real one. In that sense, a text, too, is a shadow. It is the reflection and recreation of the author's thoughts and imagination in written version. Wordsworth has rightly defined poetry as a "spontaneous overflow of powerful feelings recollected in tranquility". The same definition applies to any literary piece. Even 'stream of consciousness' is one kind of recreation as the process includes thoughtful organization of writing afterwards. If that is the practical nature of a text and its writer, there is no text and no author that we can consider as original. If the vise-versa is true, we will have to recognize the translator, too, as an author in her/his own right.

\section{The Author/Translator Hierarchy}

To justify the stance that a translator is equally active as an author, Jaques Derrida's concept of deconstruction comes into play at this stage. Deconstruction has become associated with the attempt to expose and undermine the oppositions, hierarchies, and paradoxes on which particular texts, philosophical and otherwise, are founded (Benjamin 2004). Derrida (1981) postulated this strategy as a manner of considering everything along with its opposite phase. He considered that "classical philosophical opposition", can never have "peaceful coexistence" of the two opposing concepts; instead, they are ordered in a "violent hierarchy"-

"...in a classical philosophical opposition we are not dealing with the peaceful coexistence of a vis-à-vis, but rather with a violent hierarchy. One of the two terms governs the other (axiologically, logically, etc.), or has the upper hand" (p. 41).

The theory of deconstruction attempts to outdate the centre/periphery, male/female, white/black, normal/abnormal, author/translator, of course, and other sets of binary opposites that often place the privileged ones from the sets at the centre. Thus the ones at the centre enjoy power over the ones at the periphery that eventually consolidate a particular ideology of a cultural construct. Following this strategy we can dethrone the 'author' from the centre and push it to the periphery while placing the 'translator' at the centre by overturning the hierarchical binary of author/translator so that the task of a translator is no longer estimated as a secondary activity in relation to that of an author.

Itamar Even-Zohar is another theorist of translation who scorns "the fallacies of traditional aesthetic approach" to translation (as cited in Munday 2001: 109). He postulates polysystem theory in the light of the Russian formalists where he promotes that translated literature is also a system in the literary system in a society. In the hierarchy of this polysystem, the positions of the conservative and innovative literature are not ultimate and fixed: rather, they are always at the risk of losing their status anytime. Thus the translated literature may suddenly occupy the primary position in the polysystem. Translations may also contribute to the formation of "new models for the target culture, introducing new poetics, techniques and so on" (Munday 2001: 110). This may lead one day to consider translation literature as a separate genre in the literary system. Then there will be no debate about the status of a translator.

\section{THE 'DEATH' OF A TEXT}

Roland Barthes (n.d.) in his "The death of the author" has rightly judged the status of an author when he claims that when writing begins, the author enters into her/his own death. He clarifies that writing 
On Demanding the Authorship of a Translator: A Scrutiny of why and how the Translator should be Judged in Relation to the Author

is a performance of language which is always elusive because of its multilevel meanings. In case of a text, there are only levels of meanings, but none of them is ultimate or can be taken for granted. We can consider it only in terms of how far and deep its meaning can range. Writing does not promise any secret. Any refusal to a fixed meaning of a text means to refuse the existence of its creator or the author. The author does not make a text live long. It is the reader who gives a text its future. The reader consolidates the multilevel feature of a text. As soon as a person finishes writing, s/he is dead. Where the author dies, the reader is born- "the birth of the reader must be ransomed by the death of the Author" (p. 6).

Barthes's view has been extended further by Foucault in his "What is an author?" He contends that a text is a sum total of signs where one signifier may refer to multiple signified objects and concepts at the same time. It is the writer who decides the meaning of a text that can be completely different from the author's intended one. Thus the text becomes the murderer of the author. The signs used by an author often betray him by creating different meanings. He is killed by his own signs. By the word 'death', Foucault means that the author is decentred. It is the reader who cracks the cocoon created by the author open and sets the text free. We should not forget at this point that the translator is at first a reader or audience. Whatever claims and characteristics of a reader have been highlighted above apply equally to the translator. That is to say: "Prospective audiences differ both in decoding ability and potential interest" (Nida 2000: 155). It is the reader-cum-translator who replaces the author by giving the text another meaning, and ultimately another life.

\section{TRANSLATION AS RECREATION}

This is the ground on which we will find some other justifications on behalf of our claim. Firstly, a translation is always a re-creation. I am concerned with the term 're-creation' as long as it takes creativity into account. Toper (2010) views translation as a genre of literary creativity in which a work written in one language is re-created in another. As we see in other aesthetic forms such as music, painting, and dance, language does not hinder the accessibility because of their visual nature. However, his claims that "in literary translation, language has more than a communicative, or social and connective purpose... it has an aesthetic function". (Toper, 2010: para. 2). As soon as language transcends its linguistic function towards an aesthetic function, it demands creativity from the part of the translator. Toper continues-

Literary translation differs from literary creativity in that its existence depends on the existence of an object of translation, a work to be translated. However, in the actual literary process, it is not always possible to draw a distinct boundary between translation and all creative literature. (para. 2)

While scrutinizing the Italian translation of James Joyce's Finnegans Wake, S. Zanotti (2006) refers to Luigi Schenoni's interview where Schenoni asserts that-

I might be immodest but I have to say that my translation is really a re-creation of Joyce's work, because I try to render it in a language equivalent to the one he used, normally called wakese; the language I create is a wakese based on Italian [R]. It does need some creativity. [R] After all, I am a poet, even when I translate $F W$ (as cited in Zanotti 2006: 3)

A translator has to recreate the linguistic devices such as similes, metaphors, ironies, and imagery in the target language since "no two languages are very sufficiently similar to be considered as representing the same social reality". (Sapir, as cited in Bassnett 1980: 21) While doing so, s/he has to invent or create new devices for the lack of equivalent ones.

A translation is a kind of reincarnation of a text. According to Walter Benjamin (2000), a translation comes later than the original, and since the important works of world literature never find their chosen translators at the time of their origin, their translation marks their stage of continued life (p. 76). Venutti (2000) interprets Benjamin's view by saying that 'a translation participates in the 'afterlife' of the foreign text, enacting an interpretation" which "does more than transmit messages; it recreates the values that accrued to the foreign text over time." (p. 71). It implies that translation is a kind of resurrection of the original text that is executed by the translator. S/he gives life to the original text for the second time. From this point of view, s/he is as important as the author.

Translation involves semantic transfer between two languages. It is a reinventive transmission of a text. (Campbell 2011: 3). It is an act where complete faithfulness to the author or the source text is 
On Demanding the Authorship of a Translator: A Scrutiny of why and how the Translator should be Judged in Relation to the Author

impossible- "it stands to reason that there can be no absolute correspondence between languages. Hence there can be no fully exact translations." (Nida 2000: 153). Venutti (2000) observes that literary criticism "emphasizes the impossibility of reproducing a foreign literary text in another language which is sedimented with different literary styles, genres, and traditions" (p. 112). He draws on Nabokov on this occasion who assures that an ideal version of the original text is ultimately unattainable (p. 112). After judging the possibilities of equivalence between the original and translated texts, Roman Jacobson (2000) in his "On Linguistic Aspects of Translation" also declares that translating poetic art is technically impossible. He continues that "poetry by definition is untranslatable. Only creative transposition is possible" (p. 143). One reason is because it is very difficult and often impossible to stick to the "word-for-word' ideal while translating a text. In any kind of translation some amount of fabrication is there, be it in the form or content. Even translation of scientific texts cannot display this ideal completely. Different theorists talk on behalf of faithfulness, but ultimately stray from this principle at the time of practical application.

The process of translation is similar to the process of hybridization where two different languages encounter, compromise, and are mutually put together that gives birth to a completely new piece of writing, but at the same time it carries the features of both. A translator is an author in the sense that $\mathrm{s} / \mathrm{he}$, in cooperation with the author of the original text, produces something that displays imprints of both its creators. "Translation thus becomes an act of cooperation between the author and his translator, who can call himself an artist, a creator, or ... a poet.'(Zanotti 2000: 7).

The terminologies that have been used so far by the theorists are characterized by the prefixes "trans-" and "re-"- for example, "Fernando Ortiz's and Ángel Rama's concept of 'transculturation', Octavio Paz's use of translation as 'transformation' and 'recreation', and, especially Haroldo de Campos's various neologisms, including 'transcreation', 'transtextualization', 'transparaization', 'transillumination', and most provocatively, 'transluciferation mefistofáustica'”. (Gentzler 2003: 27). The prefixes themselves imply that the task of a translator is to reproduce the original text while transcending its boundary at the same time. In his article "Translations Without Border", Edwin Gentzler (2012) senses that-

... the translators are not taking something from one culture and carefully bringing it across intact, but instead transforming, reformulating, incorporating, devouring a text, making it one's own, and reproducing it in their own language and on their own terms. The metaphor that works best for me is one in which translation is not seen as a form of importing a text from the outside, but rather drawing upon reserves and experiences from within each individual and one's own multicultural heritage (para. 4).

He maintains further that unlike a mechanical activity, translation acts as a living matter that is not anymore restricted to 'us' and 'them,' and that merges the border between 'self' and 'other'.

He provides an example that he takes from Myriam Salma-Carr's essay entitled "Translation into Arabic in the "Classical Age", on the Baghdad School of Translation during the ninth and tenth centuries when "translators were viewed as scholars in their own rights, at the same level as authors"-

Scholars having taken the transnational turn in translation studies are interested in the connection of translation to the construction of displaced peoples' cultural identity and are undertaking studies that illustrate the primary rather than secondary role of translation in the construction of culture. (para. 21)

\section{CONCLUSION}

It is very obvious that it is still a long way to reach the aim of establishing the translator as the author of the translated text. It is not at all possible to accomplish the task of translation without exercising some amount of freedom against the traditional restrictions set by the theorists. Newmark (1998) asserts, "Translation is not and never will be a science" (p. 185). Complete equivalence between the original and translated texts is also unattainable. Wherever there is a question of translation, the interference of creativity is inevitable. Where there is creation, there must be a creator. Translation is no doubt a creation performed by the translator. If the creator of the original text is considered as the author, the creator of the translated text should also be evaluated equally with the author side by side. While the debate continues, we should not forget that most of the theories of translation studies are themselves English translations of German, Russian, Arabian, and Hebrew articles, essays and books. 
On Demanding the Authorship of a Translator: A Scrutiny of why and how the Translator should be Judged in Relation to the Author

\section{REFERENCES}

[1] Barthes, Roland. (n.d.) "The Death of the Author". Trans. Richard Howard. Web. 22 Feb. 2013. http://evans-experientialism.freewebspace.com/barthes06.htm

[2] Bassnett, Susan, (1980): Translation Studies. London: Routledge. Print. Benjamin, Ross. "Hostile Obituary for Derrida", The Nation, November 24, 2004. <http://www.thenation.com /article/hostileobituary-derrida\#>. 22 Feb. 2013.

[3] Benjamin, Walter, (2000): The Task of the Translator: An Introduction to the Translation of

[4] Baudlaire's Tableaux Parisiens". The Translation Studies Reader. Ed. Lawrence Venuti. New York: Routledge. 75-85. Print.

[5] Campbell, Laura, Jane, (2011). Translation and Rcriture in the Middle Ages: Rewriting Merlin in the French and Italian Vernacular Traditions. Doctoral thesis, DurhamUniversity.

[6] Chamberlain, Lori, (2000): "Gender and the Metaphorics of Translation". The Translation Studies Reader. Ed. Lawrence Venuti. New York: Routledge. 306-321. Print.

[7] Derrida, Jacques, (1981): Positions. Trans. Alan Bass. Chicago: University of Chicago Press.

[8] Eliot, Thomas Stearns, (1921): The Sacred Wood. New York: Alfred A. Knopf; Bartleby.com, 1996www. bartleby.com/200/sw4.html\#4 (accessed on 22 February 2013). "Famous Scots - Michael Scott the Wizard (? - 1236?)". (n.d.). Web. 15 Dec. 2017. http://www. rampantscotland.com/famous/blfamwizard.htm

[9] Foucault, Michael. "What Is an Author”. Trans. Josuè V. Harari. Web. 22 Feb. 2013. https://wiki.brown.edu/ .../download/.../FoucaultWhatIsAnAuthor.pdf.

[10] Gentzler, Edwin (2003). "Translation, Postcolonial Studies, and the Americas," EnterText, 2:2, http://www .brunel. ac.uk /faculty/arts/EnterText/issue_2_2.htm (accessed on 25 September 2013). ---(2012). "Translation Without Borders". Translation, 1. Web. 22 Feb. 2013. http://translation.fusp.it/articles /translation -without-borders

[11] Jacobson, Roman, (2000): “On Linguistic Aspects of Translation”. The Translation Studies Reader. Ed. Lawrence Venuti. New York: Routledge. 138-143. Print.

[12] Kristeva, Julia, (1986): "Word, Dialog and Novel". The Kristeva Reader. Ed. Toril Moi. New York: Columbia University Press. 34-61. Print.

[13] Munday, Jeremy, (Ed.), (2001). Introducing Translation Studies: Theories and Applications. London: Routledge

[14] Newmark, Peter, (1998): A textbook of Translation. New York: Prentice Hall.

[15] Nida, Eugene, (2000): "Principles of Correspondence". The Translation Studies Reader. Ed.Lawrence Venuti. New York: Routledge. 153-167.

[16] Plato, (1987): The Republic. 2nd ed. Trans. Desmond Lee. New York, NY: Penguin Books.

[17] Toper, P. M., (2010): "Literary Translation". The Great Soviet Encyclopedia, (3rd Ed.) (1970- 1979).New York: The Gale Group, Inc. Web. 22 Feb. 2013. http://encyclopedia2.thefreedictionary.com/ Literary + Translation

[18] Venuti, Lawrence, ed., (2000): The Translation Studies Reader. New York: Routledge. Print.

[19] Zanotti, Serenella, (2006): "The Translator's Visibility: The Italian Translations of Finnegans Wake”. Web. 22 Feb. 2013. http://www.mediazionionline.it/dossier/2006zanotti_print.htm.

\section{AUTHORS' BIOGRAPHY}

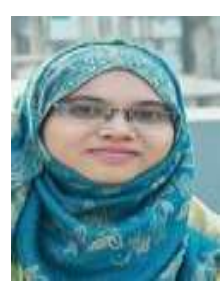

Mossa. Sohana Khatun is an Adjunct Lecturer in the Department of English Literature and Language (ELL), Northern University (NUB), Dhaka, Bangladesh. She is a graduate of Jahangirnagar University, Dhaka, Bangladesh with Master's degrees in both English Literature and TESOL. She is experienced in institutional as well as research areas with three publications.

Citation: Mossa. Sohana Khatun "On Demanding the Authorship of a Translator: A Scrutiny of why and how the Translator should be Judged in Relation to the Author" International Journal on Studies in English Language and Literature (IJSELL), vol 6, no. 1, 2018, pp. 19-24. doi:http://dx.doi.org/10.20431/23473134.0601003 .

Copyright: (C) 2018 Authors. This is an open-access article distributed under the terms of the Creative Commons Attribution License, which permits unrestricted use, distribution, and reproduction in any medium, provided the original author and source are credited. 